\title{
Development of multi-component counseling program for enhancing resilience among Thai caregivers of older persons with dementia
}

Enhancing resilience among Thai caregivers

Thidajit Maneewat

Department of Research and Development, Suratthani Hospital, Suratthani, Thailand

Somrat Lertmaharit

Preventive and Social Medicine, Faculty of Medicine, Chulalongkorn University, Bangkok, Thailand

Sookjaroen Tangwongchai

Psychiatry, Faculty of Medicine, Chulalongkorn University, Bangkok, Thailand, and

Phenphop Phansuea

Institute of Nutrition, Mahidol University, Bangkok, Thailand

\begin{abstract}
Purpose - The purpose of this study was to develop a multi-component counseling program and examine the short-term effects of an 8-session program.

Design/methodology/approach - This present study was a research and development of a multicomponent counseling program for enhancing resilience. The concept of resilience was reviewed based on a synthesis of existing research, together with an exploration of qualitative data derived from an interview with ten caregivers of older persons with dementia. Six domains of resilience were identified: physical, relationships, emotional, moral, cognitive and spiritual; which were then used to develop the eight-week program. The program was examined by a panel of three experts for content validity, which yielded an index of 0.87 . The program was then tried out with 60 caregivers recruited and assigned 30 caregivers in the intervention and control group. The Caregiver's Resilience Scale (CRS) was used by trained nurses to evaluate the program and data were analyzed using repeated measures ANOVA.

Findings - The results indicated that the resilience scores of the participants in the intervention group were statistically significantly higher than those of the control group at one month after program participation and at the follow-up three months later $(p<0.05)$.

Originality/value - It could be concluded that the program yielded support for the evidence-based practice of non-pharmacological intervention. The program would be suitable as a clinical practice guideline to provide help to caregivers of older persons with dementia at the outpatient setting.
\end{abstract}

Keywords Multi-component counseling program, Resilience, Caregivers, Older person, Dementia

Paper type Research paper

(C) Thidajit Maneewat, Somrat Lertmaharit, Sookjaroen Tangwongchai and Phenphop Phansuea. Published in Journal of Health Research. Published by Emerald Publishing Limited. This article is published under the Creative Commons Attribution (CC BY 4.0) licence. Anyone may reproduce, distribute, translate and create derivative works of this article (for both commercial and non-commercial purposes), subject to full attribution to the original publication and authors. The full terms of this licence may be seen at http://creativecommons.org/licences/by/4.0/legalcode

The authors gratefully acknowledge the funding support provided by the Ratchadaphiseksomphot Endowment Fund of Chulalongkorn University (RES560530130-AS), Bangkok, Thailand. The authors are thankful to all the caregivers of older persons with dementia who participated in this study for their cooperation throughout the study.

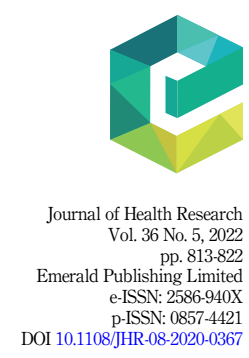

Received 29 August 2020 Revised 21 November 2020 22 January 2021

Accepted 18 April 2021

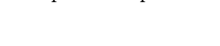


JHR

36,5

814

\section{Introduction}

At present, advances in medical technology in Thailand have improved both medical treatment and diagnoses. The development of public health services, such as health promotion and healthcare, focus on populations in certain age groups with the aim of decreasing mortality rates and increasing people's longevity. As a result, the change in the population pyramid toward an aging society has been expected, and it is estimated that by the year 2027, nearly 17 million Thai people will be in the elderly population [1]. In fact, there is a high incidence of the physical illness of dementia that is associated with elderly people and longevity, an illness which affects both the physical and psychological wellbeing of many in the aging population. Dementia is a part of the global cognitive impairment issue associated with aging. It does not result in alteration of an individual's consciousness, but leads to functional decline in elderly persons [2]. In general, dementia progresses over time, causing both behavioral and psychological symptoms of dementia (BPSD) in those who have developed the illness. The BPSD syndrome is composed of psychological symptoms (delusion, hallucination, misperception, sadness, apathy, anxiety and change in sleep patterns) and behavioral symptoms (wandering, agitation, catastrophic reaction, complaining, dis-inhibition, intrusiveness and negativism). When an older person has BPSD, their symptoms can be a cause of both stress and distress in caregivers, particularly when the patients exhibit cognitive and functional decline [3].

Furthermore, previous studies have shown that the effects of dementia on caregivers include chronic stress, depression, distress, decreased quality of life, loss of social relationship and impaired immunologic and hormonal functioning, all of which are outcomes which are collectively perceived as the "caregivers" burden' $[4,5]$. However, it is worth noting that some research studies have reported positive effects resulting from caregivers, which include psychological wellbeing, satisfaction, good attitude, perceived good relationship, self-esteem and self-appreciation [6]. The factors that are related to the caregivers' burden include levels of activities of daily living (ADL), instrumental activities of daily living (IADL), BPSD and impaired cognition when dementia progress decreases ADL, poor cognition and increased BPSD, all of which are factors which manifest how older persons become highly dependent on their caregivers for complete assistance [7, 8].

In order to prevent caregivers' burnout, their physiological and psychological stress levels need to be reduced, and their ability to confront caregiving tasks for demented older persons living at home needs to be promoted. A review of previous research associated with the caregivers' burden issue has revealed that resilience is one of the key buffers and protective factors protecting caregivers against burnout and strain, as resilience is able to decrease caregivers' burden and distress $[9,10]$. These "resilient" caregivers have good coping abilities and can develop strength from the stress and trouble that they are facing. In addition, caregivers who have resilience, also have the ability to seek meaning, goals and values when dealing with complicated situations $[11,12]$. Enhancing resilience through a specific program is one of the ways that aims to assist and support the caregivers of persons with dementia.

A review of existing research has shown that a multi-component program appears to be more effective to enhance caregivers' resilience, as it offers a combination of counseling, support and education [13]. Moreover, the program should be structured to include multicomponent interventions and positive outcomes for both caregivers and older persons with dementia $[14,15]$. The multi-component interventions appear to be more effective than narrowly focused ones and program designed for individual needs appear more effective than generic program [16]. The elements of multi-component caregivers' interventions involve active provision of information, didactic instruction and role playing. The statistically significant effects of multi-component interventions could improve the caregivers' performance regarding self-efficacy, depression, subjective wellbeing and perceptions of burden [17]. 
It is worth noting that most studies on caregivers' resilience have been conducted in western countries and, at present, no research has been done on enhancing resilience with Thai caregivers of older persons with dementia. Furthermore, before designing the program, factors related to enhancing resilience should be considered. These factors include cultural, religious and Thai caregivers' socio-demographic characteristics, as well as the clinical characteristics of older persons with dementia, the contexts of health services and characteristics and settings of healthcare professionals.

In this study, tailoring the program to serve individual caregivers' needs and timing so that individual personal learning and coping skills would be supported. Caregivers of older persons with dementia received health education and support in the form of information, skills practices, coping strategies and individual health counseling, all of which enabled caregivers to handle their caregiver role.

\section{Methods}

This present study was a research and development aimed to develop a multi-component counseling program and examine the short-term effects of an eight-session program. The methodology of this study was divided into two phases. The first phase was program development and the second was the examination of the short-term effects of the eightsession program (Figure 1).

\section{Phase 1: program development}

Step 1: Establishment of the domain structure of the multi-component counseling program.

The program was developed by the researchers. The concept of resilience theory [18] was reviewed based on a synthesis of existing research, together with an exploration of qualitative data derived from an interview with ten caregivers of older persons with dementia. Six domains of resilience's theory were identified as physical, relational, emotional, moral, cognitive and spiritual; these were then used to develop the program. The program was tailored with eight sessions of the intervention, including: session one: engagement; session two: promoting self-care; session three: communication skills training; session four: relaxation techniques; session five: managing physical care; session six: managing skills training; session seven: religious support; and session eight: termination.

Step 2: Evaluation of the quality of the program.

The quality of the program was validated by three experts: two were psychiatrists who had specialized in geriatric psychiatry, and one is a psychologist who specialized in psychology

\begin{tabular}{|l|l|l|}
\hline Week & Session & \multicolumn{1}{|c|}{ Program } \\
\hline $\mathbf{1}$ & 1 & engagement \\
\hline $\mathbf{2}$ & 2 & promoting self-care \\
\hline & 3 & communication skills \\
\hline $\mathbf{4}$ & & training \\
\hline $\mathbf{5}$ & 4 & relaxation techniques \\
\hline $\mathbf{6}$ & 5 & managing physical care \\
\hline $\mathbf{7}$ & 6 & managing skills training \\
\hline $\mathbf{8}$ & 7 & religious support \\
\hline & 8 & termination \\
\hline
\end{tabular}

Figure 1. Multi-component counseling program for enhancing resilience 
JHR

36,5

816

and who had experience related to program counseling. These experts examined the program in terms of accuracy, language use and internal consistency with definitions of terms. Using the Content Validity Index (CVI) a rating equal to 0.8 or higher indicated that the program was valid [19]. These experts examined the program in terms of accuracy, language use and internal consistency with definitions of terms. The validation form for content validity required the three experts to give their opinions and comments on the relevancy and clarity of the contents by giving professional scores using a "four-point rating scale" ( 1 = not relevant, $2=$ somewhat relevant, $3=$ quite relevant and $4=$ very relevant).

Phase 2: examine the short-term effects of the eight-session program

The participants who met the inclusion criteria consisted of 60 caregivers; 30 caregivers were assigned to an intervention group and 30 caregivers to a control group. All participants were informed of the study's objective and the procedure for data collection. They were also given an opportunity to ask questions in order to clear any doubts, and consent forms were signed following the researcher's explanation.

The control group $(n=30)$ received standard care, including individual health education and a caregivers' handbook about caring for older persons with mild to moderate dementia. They were asked to complete the Caregivers' Resilience Scale (CRS) three times: the first time at baseline (T1), once again after two months (T2) and for the last time after three months were followed up (T3).

The intervention group $(n=30)$ participated in the eight program sessions (duration 45 minutes to 1 hour per session, over 8 weeks), organized by the program in parallel with the control group and conducted by researchers and nursing assistants.

Each session of the program emphasized the sharing of caregivers' experiences, support, learning principles of modeling, role playing, practice and feedback and homework assignments. The program was conducted with individual health counseling by the researcher and the researcher's nurse assistants. For this group, the participants were asked to complete the CRS three times: the first time at the baseline (T1), once again after completion of the eight weekly individual sessions (T2) and after three months at the following up (T3).

Study design

The study design was a quasi-experiment.

\section{Setting and sample}

The research setting was the Memory Clinic and Medical-neurological Clinic at the OutPatient Department of Surat Thani Hospital, located in Surat Thani Province, Thailand, which has the responsibility for taking care of dementia patients in the upper southern area of Thailand. The target population consisted of primary caregivers of older persons who had been diagnosed with mild to moderate dementia, or any subtypes of dementia, from February 2016 to August 2016.

The participants were recruited by purposive sampling based on the inclusion criteria set as follows: (1) they were a primary caregiver who provided the majority of care to older persons with dementia for at least eight hours per day; (2) they were between 20 and 60 years of age; (3) they were primary caregivers of older persons with mild to moderate dementia who had been diagnosed by a neurologist; (4) they were able to speak and understand the Thai language; (5) they were able to participate in all eight sessions of the program; (6) they had their first experience of their caregivers' role; (7) they had been providing care to older persons with dementia for at least six months; and (8) they were living in Surat Thani Province. On the 
other hand, the exclusion criteria were: (1) they received other treatment to control their mental illnesses including mood disorder and anxiety; and/or (2) they were hired caregivers.

The sample size calculation was based on the power analysis for experimental research, with the desired standard power of 0.80 as the minimum acceptable power for the study [20, 21]. The minimum level of significance was set at 0.05 and the effect size was equal to 0.5 (medium effect size), with an additional $20 \%$ for attrition. Therefore, the final sample size was 30 participants in each group, and the total number of participants of the study was 60.
Enhancing resilience among Thai caregivers

\section{Data collection}

The instruments used in data collection were: (1) a demographic data questionnaire composed of 12 closed-ended questions; (2) the CRS composed of 30 items arranged in a 4-point rating scale ranging from 0 to 3 . The scoring criteria for positive statements were as follows: $0=$ not true, $1=$ sometimes true, $2=$ frequently true and $3=$ mostly true. On the contrary, the criteria for negative statements were as follows: $0=$ mostly true, $1=$ frequently true, $2=$ sometimes true and $3=$ not true.

\section{Ethical consideration}

Protection of human subjects was sought from the Institutional Review Board (IRB), the Ethics Review Committee for Research Involving Human Research Subjects, Health Science Group I, (ECCU1) Chulalongkorn University (COA No. 063/2557) and the Ethics Committee of Surat Thani Hospital. The participants were approached and informed of the study.

\section{Data analysis}

Descriptive statistics including frequency distribution, percentage, range, mean and standard deviation were used to describe the socio-demographics data. In addition, the independent t-test and chi-square test were used to analyze continuous and categorical variables to compare baseline data between the intervention group and the control group. Data of caregivers' resilience were analyzed using repeated-measures analysis of variance (repeated-measures ANOVA). Repeated-measures ANOVA were employed to examine the effects of the treatment by time and the patterns of change. Univariate assumptions regarding the dependent variable were analyzed for normality and homogeneity of variance. Assumptions of the Mauchley's test for sphericity were met. The mean scores of resilience of caregivers obtained during the baseline (T1), one month (T2) and three months follow-up (T3) were compared using the $F$-test with repeated measure ANOVA. Significance for the Repeated-measures ANOVA analysis was set at $p<0.05$. Data checking for missing values and outliers was done before analysis.

\section{Results}

The first phase - the CVI - was equal to 0.87 . In the revision process, the program was revised and improved by the researcher based on the comments and recommendations of the experts. The managing physical care session was revised using the usual guideline on care of ADL and IADL. The contents of the "managing skills" training session were changed, with an addition of a guideline on problem-solving and a revision of the contents of a case study to facilitate role playing and to ensure effective management.

The results revealed that there were no statistically significant differences in baseline demographic characteristics between the intervention and control groups (Table 1).

The mean scores of the participants in the intervention group increased at baseline (T1), one month (T2) and three months (T3) (mean = 43.30, $\mathrm{SD}=12.82$; mean = 75.00, $\mathrm{SD}=13.30$; and mean $=80.37, \mathrm{SD}=18.46$, respectively). The control group at baseline (T1), one month 
JHR

36,5

\begin{tabular}{|c|c|c|c|c|c|}
\hline Variables & $\begin{array}{l}\text { Intervention group } \\
\quad(n=30) n(\%)\end{array}$ & $\begin{array}{c}\text { Control group }(n=30) \\
n(\%)\end{array}$ & $T$-test & $\chi^{2}$ - test & $p$-value \\
\hline $\begin{array}{l}\text { Gender } \\
\text { Male } \\
\text { Female }\end{array}$ & $\begin{array}{r}5(16.67) \\
25(83.33)\end{array}$ & $\begin{array}{r}6(20.00) \\
24(80.00)\end{array}$ & & 0.49 & 0.58 \\
\hline $\begin{array}{l}\text { Age (yrs.) } \\
<40 \\
40-50 \\
51-60 \\
\text { Mean (SD) }\end{array}$ & $\begin{array}{c}6(20.00) \\
15(50.00) \\
9(30.00) \\
48.56(8.56)\end{array}$ & $\begin{array}{l}5(16.67) \\
14(46.67) \\
11(36.66) \\
49.60(10.13)\end{array}$ & 0.68 & & 0.56 \\
\hline $\begin{array}{l}\text { Education } \\
\text { Lower than bachelor } \\
\text { Bachelor's degree }\end{array}$ & $\begin{array}{r}25(83.33) \\
5(16.67)\end{array}$ & $\begin{array}{r}26(86.67) \\
4(13.33)\end{array}$ & & 5.06 & 0.08 \\
\hline $\begin{array}{l}\text { Occupation } \\
\text { Agriculturist } \\
\text { Trader } \\
\text { Government official }\end{array}$ & $\begin{array}{l}24(80.00) \\
4(13.30) \\
2(6.70)\end{array}$ & $\begin{array}{l}25(83.30) \\
3(10.00) \\
2(6.70)\end{array}$ & & 0.16 & 0.92 \\
\hline $\begin{array}{l}\text { Religion } \\
\text { Buddhism } \\
\text { Islam }\end{array}$ & $\begin{array}{r}25(83.30) \\
5(16.70)\end{array}$ & $\begin{array}{r}26(86.70) \\
4(13.30)\end{array}$ & & 0.13 & 0.72 \\
\hline $\begin{array}{l}\text { Average family income } \\
10,000-25,000 \\
25,001-40,000\end{array}$ & $\begin{array}{l}\text { ber month) } \\
20(66.67) \\
10(33.33)\end{array}$ & $\begin{array}{r}21(70.00) \\
9(30.00)\end{array}$ & 2.37 & & 0.77 \\
\hline $\begin{array}{l}\text { Vacation } \\
\text { Yes }\end{array}$ & $30(100)$ & $30(100)$ & & NA & \\
\hline $\begin{array}{l}\text { Marital status } \\
\text { Single } \\
\text { Married } \\
\text { Widowed }\end{array}$ & $\begin{array}{c}1(3.30) \\
28(93.40) \\
1(3.30)\end{array}$ & $\begin{array}{r}- \\
27(90.00) \\
3(10.00)\end{array}$ & & 2.35 & 0.50 \\
\hline $\begin{array}{l}\text { Number of hours of care } \\
6-12 \\
13-18 \\
19-24\end{array}$ & $\begin{array}{l}g(\text { per day) } \\
18(60.00) \\
9(30.00) \\
3(10.00)\end{array}$ & $\begin{array}{c}17(56.67) \\
11(36.66) \\
2(6.67)\end{array}$ & 4.96 & & 0.20 \\
\hline $\begin{array}{l}\text { Relationship with older pe } \\
\text { Spouse } \\
\text { Son } \\
\text { Daughter }\end{array}$ & $\begin{array}{l}\text { s with dementia } \\
\qquad \begin{array}{l}2(6.67) \\
5(16.67) \\
23(76.66)\end{array}\end{array}$ & $\begin{array}{c}2(6.67) \\
6(20.00) \\
22(73.33)\end{array}$ & & 4.16 & 0.82 \\
\hline $\begin{array}{l}\text { Duration of caregiving (n } \\
24-36 \\
37-48 \\
49-60\end{array}$ & $\begin{array}{l}19(63.30) \\
9(30.00) \\
2(6.67)\end{array}$ & $\begin{array}{r}17(56.70) \\
10(33.30) \\
3(10.00)\end{array}$ & 1.45 & & 0.35 \\
\hline $\begin{array}{l}\text { Responsibility for care } \\
\text { Alone } \\
\text { Having assistance from } \\
\text { others } \\
\text { Note(s): NA = not appl }\end{array}$ & $\begin{array}{r}5(16.67) \\
25(83.33)\end{array}$ & $\begin{array}{r}4(13.33) \\
26(86.67)\end{array}$ & & 5.30 & 0.88 \\
\hline
\end{tabular}

Table 1.

Demographic characteristics of participants in the intervention group and the control group $(n=60)$

\section{8}


(T2) and three months (T3) (mean $=44.67, \mathrm{SD}=12.56$; mean $=70.17, \mathrm{SD}=13.02$; and mean $=74.27, \mathrm{SD}=11.42$, respectively) (Table 2 ).

The statistically significant difference by group alone was at the 0.05 level $(\phi>0.05)$ (Table 3). Pairwise comparisons in the overall intervention group's mean scores of resilience obtained at baseline (T1), one month (T2) and three months (T3) were statistically significantly different $(\phi<0.001)$.

\section{Discussion}

From the results, most caregivers of older person with dementia are women and a daughter. There are a few who are sons. Sons' caregivers have a greater burden of care than husband caretaker. Although it takes less time to take care of it. Including having problems, difficulties and stress in taking care of parents with dementia. There is also a lack of intervention support programs [22].

The mean scores of the participants in the intervention group increased at the baseline (T1), one month (T2) and three months (T3), suggesting that the multi-component counseling program could be used to enable caregivers to cope effectively with dementia in the elderly and could enhance those caregivers' resilience levels which are supported by previous metaanalysis study about effectiveness of non-pharmacological interventions for informal

\begin{tabular}{lccc}
\hline Time point & Intervention group mean (SD) & Control group mean (SD) & Total mean (SD) \\
\hline Baseline & $43.30(12.82)$ & $44.67(12.56)$ & $43.98(12.76)$ \\
1 Month & $75.00(13.30)$ & $70.17(13.02)$ & $73.58(13.16)$ \\
3 Months & $80.37(18.46)$ & $74.27(11.42)$ & $78.68(13.09)$
\end{tabular}

Note(s): At baseline (T1), one month (T2) and three months (T3) after entering the program by time between the intervention group $(n=30)$ and the control group $(n=30)$
Enhancing resilience among Thai caregivers

\begin{tabular}{lrrrrr}
\hline Source & SS & df & \multicolumn{1}{c}{ MS } & $F$ & $p$-value \\
\hline Time & 413.200 & 2 & 206.600 & 156.570 & $<0.001$ \\
Time X group & 168.400 & 2 & 84.200 & 63.810 & $<0.001$ \\
Error (Time) & 153.067 & 116 & 1.320 & &
\end{tabular}

Note(s): At baseline, one month, and three months after entering the program by time between the intervention group $(n=30)$ and the control group $(n=30)$ (Test of within-groups)

Table 2.

Comparison of resilience scores

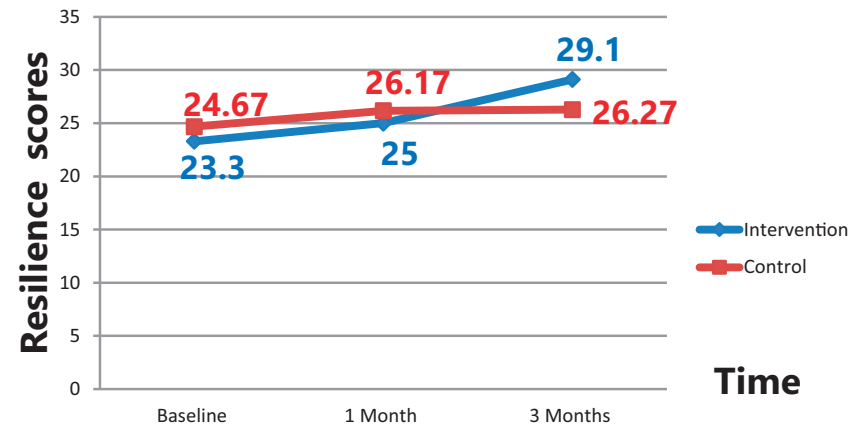

Figure 2.

The mean scores of resilience between the intervention group and the control group at baseline (T1), one month (T2) and three months (T3) resilience scores (Test of within-groups) 
JHR

36,5

820

dementia caregivers [23]. Additionally, resilience could increase caregivers' competence; selfcare efficacies were promoted to ensure the continued provision of suitable care. Remarkably, there was a significant difference in resilience scores at 3 months between the intervention and control groups. This difference may be explained as resulting from the eight intervention sessions. The intervention group participated in the program for a period of eight weeks and these interventions were like the six domain of resilience that appeared adequate reinforcement, which were the eight components of the program that could enhance resilience and clear instruction.

The result from this study is congruent with a previous study which reported that reduced caregivers' impact from caregiving elderly with behavioral and psychological symptoms of dementia such as depression and improve quality of life [24, 25]. Moreover, the conclusion from the systematic research review showed that using practical skills and discussion for effective intervention could improve caregivers' knowledge and communication [26, 27].

Specific interventions are needed for improved quality of life and psychological wellbeing for caregivers of older persons with dementia, specifically, as their resilience levels increased. The Multi-component Counseling Program is an alternative to the Thai caregivers of older persons with dementia.

\section{Conclusion}

The results confirmed that the multi-component counseling program was effective to enhance resilience in caregivers of older persons with dementia in Thailand. This study would be significant to healthcare professionals, especially physicians, nurses and other healthcare professionals, as the findings of the study could be implemented in the clinical practice guideline.

\section{Limitation and recommendations}

This study was a short-term program, and the duration of the study was not long enough for a comprehensive evaluation of the effectiveness of the program in such areas as prevention of depression or decrease in caregiver burden. Thus, a longitudinal study using a mixed-method research design should also take place. For example, a study may combine a controlled trial with a longitudinal study, with a longer follow-up period. Also, a qualitative research approach is recommended to examine the long-term effects of a multi-component program, not only on improvement of resilience but also on prevent of depression and decrease in burden.

Also, the future program should be designed to include specific interventions such as communication skills training, managing physical care and managing skills training.

Conflicts of Interest: None

\section{References}

1. Mahidol University, Institute for Population and Social Research. Thai population in the future. [cited 2019 Jun 1]. Available from: http://www.ipsr.mahidol.ac.th/ipsrbeta/th/Index.aspx.

2. Pathak KP. An overview of dementia. MedDocs Publications. [updated 2018; cited 2019 May 14]. Available from: https:/meddocsonline.org/ebooks/an-overview-on-dementia/an-overview-on-dementia.pdf.

3. Shimada H, Kitamura S, Takuwa S, Yokozeni S, Tagai K, Moriguchi S, et al. Cortical tau deposition is associated with behavioral and psychological symptoms of dementia causing caregiver burden: path analysis and pet study. J Neurol Sci. 2017; 381: 779. doi: 10.1016/j.jns.2017.08.2199.

4. Vernon EK, Cooley B, Rozum W, Rattinger GB, Behrens S, Matyi J, et al. Caregiver-care recipient relationship closeness is associated with neuropsychiatric symptoms in dementia. Am J Geriatr Psychiatry. 2019; 27(4): 349-59. doi: 10.1016/j.jagp.2018.11.010. 
5. Celina GG, Hector RH, Ileana AG, Raul GH, Eduardo ME, Felix ML, et al. Relationship of stigma to caregivers burden in Alzheimer's disease patients. J Prim Health Care Gen Pract. 2018; 2(2): 024.

6. Monin JK, Schulz R, Feeney BC. Compassionate love in individuals with Alzheimer's disease and their spousal caregivers: associations with caregivers' psychological health. Gerontologist. 2015; 55(6): 981-9. doi: 10.1093/geront/gnu001.

7. Garzón-Maldonado FJ, Gutiérrez-Bedmar M, García-Casares N, Pérez-Errázquin F, Gallardo-Tur A, Martínez-Valle Torres MD. Health-related quality of life in caregivers of patients with Alzheimer's disease. Neurologia. 2017; 32(8): 508-15. doi: 10.1016/j.nrl.2016.02.023.

8. Moreno JA, Nicholls E, Ojeda N, De los Reyes-Aragon CJ, Rivera D, Arango-Lasprilla JC. Caregiving in dementia and its impact on psychological functioning and health-related quality of life: findings from a Colombian sample. J Cross Cult Gerontol. 2015; 30(4): 393-408. doi: 10.1007/ s10823-015-9270-0.

9. Scott CB. Alzheimer's disease caregiver burden: does resilience matter? J Hum Behav Soc Environ. 2013; 23(8): 879-92. doi: 10.1080/10911359.2013.803451.

10. Kuller LH, Lopez OL. Dementia and alzheimer's disease: a new direction. The 2010 Jay L. Foster Memorial lecture. Alzheimers Dement. 2011; 7(5): 540-50. doi: 10.1016/j.jalz.2011.05.901.

11. Siebert A. The resiliency advantage. [cited 2019 March 9]. Available from: https://www. bkconnection.com/static/The_Resiliency_Advantage_EXCERPT.pdf.

12. Coon DW. Resilience and family caregiving. Annu Rev Gerontol Geriatr. 2012; 32: 231-49. doi: 10. 1891/0198-8794.32.231.

13. Ducharme F. Psychoeducational interventions for family caregivers of seniors across their life trajectory: an evidence-based research program to inform clinical practice. Adv Geriatr. 2014; 2014: 316203. doi: 10.1155/2014/316203.

14. Brooks D, Ross C, Beattie E. Caring for someone with dementia: the economic, social, and health impacts of caring and evidence- based supports for carers. [updated 2015 Oct; cited 2019 Aug 19]. Available from: https://www.dementia.org.au/sites/ default/files/NATIONAL/documents/ Alzheimers-Australia-Numbered-Publication-42.pdf.

15. Hinton L, Tran D, Nguyen TN, Ho J, Gitlin L. Interventions to support family caregivers of people living with dementia in high, middle and low-income countries in Asia: a scoping review. BMJ Glob Health. 2019; 4(6): e001830. doi: 10.1136/bmjgh-2019-001830.

16. Meyer OL, Liu XL, Tancredi D, Ramirez AS, Schulz R, Hinton L. Acculturation level and caregiver outcomes from a randomized intervention trial to enhance caregivers' health: evidence from REACH II. Aging Ment Health. 2018; 22(6): 730-7. doi: 10.1080/13607863.2017.1317330.

17. Roberts E, Struckmeyer KM. The impact of respite programming on caregiver resilience in dementia care: a qualitative examination of family caregiver perspectives. Inquiry. 2018; 55 : 46958017751507. doi: 10.1177/0046958017751507.

18. Davis NJ. Resilience status of the research and research-based programs. [updated 1999; cited 2019 Feb 20]. Available from: http://www.mentalhealth.samhsa.gov/ schoolviolence/5-28resilience.asp.

19. Waltz CF, Strickland OL, Lenz ER. Measurement in nursing and health research. 5th ed. New York, NY: Springer Publishing Company; 2016.

20. Laver K, Milte R, Dyer S, Crotty M. A systematic review and meta-analysis comparing carer focused and dyadic multicomponent interventions for carers of people with dementia. J Aging Health. 2017; 29(8): 1308-49. doi: 10.1177/0898264316660414.

21. Grigorovich A, Rittenberg N, Dick T, McCann A, Abbott A, Kmielauskas A, et al. Roles and coping strategies of sons caring for a parent with dementia. Am J Occup Ther. 2016; 70(1): 7001260020p19. doi: 10.5014/ajot.2016.017715.

22. Cheng ST, Li KK, Losada A, Zhang F, Au A, Thompson LW, et al. The effectiveness of nonpharmacological interventions for informal dementia caregivers: an updated systematic review and meta-analysis. Psychol Aging. 2020; 35(1): 55-77. doi: 10.1037/pag0000401.
Enhancing resilience among Thai caregivers 
JHR

36,5

822
23. Morris L, Horne M, McEvoy P, Williamson T. Communication training interventions for family and professional carers of people living with dementia: a systematic review of effectiveness, acceptability and conceptual basis. Aging Ment Health. 2018; 22(7): 863-80. doi: 10.1080/13607863. 2017.1399343.

24. Alfakhri AS, Alshudukhi AW, Alqahtani AA, Alhumaid AM, Alhathlol OA, Almojali AI, et al. Depression among caregivers of patients with dementia. Inquiry. 2018; 55: 46958017750432. doi: 10.1177/0046958017750432.

25. Anand KS, Dhikav V, Sachdeva A, Mishra P. Perceived caregiver stress in Alzheimer's disease and mild cognitive impairment: a case control study. Ann Indian Acad Neurol. 2016; 19(1): 58-62. doi: 10.4103/0972-2327.167695.

26. Dias R, Simoes-Neto JP, Santos RL, Sousa MF, Baptista MA, Lacerda IB, et al. Caregivers' resilience is independent from the clinical symptoms of dementia. Arq Neuropsiquiatr. 2016; 74(12): 967-73. doi: 10.1590/0004-282X20160162.

27. Schoonover A. Exploring non-pharmacological interventions for behavioral symptoms of dementia: a social work perspective. Social Work Master's Clinical Research Papers 846. [updated 2018; cited 2019 Feb 15]. Available from: https://ir.stthomas.edu/ ssw_mstrp/846.

\section{Corresponding author}

Somrat Lertmaharit can be contacted at: Somrat.L@Chula.ac.th

For instructions on how to order reprints of this article, please visit our website:

www.emeraldgrouppublishing.com/licensing/reprints.htm

Or contact us for further details: permissions@emeraldinsight.com 